\title{
Exploring the Relationship between Mathematical Modelling and Classroom Discourse
}

\author{
Trevor Redmond \\ AB Paterson College \\ $<$ trd@abpat.qld.edu.au $>$
}

\author{
Joanne Sheehy \\ AB Paterson College \\ $<$ jsy@abpat.qld.edu.au>
}

\author{
Raymond Brown \\ Griffith University \\ $<$ ray.brown@griffith.edu.au>
}

\begin{abstract}
This paper explores the notion that the discourse of the mathematics classroom impacts on the practices that students engage when modelling mathematics. Using excerpts of a Year 12 student's report on modelling Newton's law of cooling, this paper argues that when students engage with the discourse of their mathematics classroom in a manner that promotes the communication of ideas, they employ mathematical modelling practices that reflect the cyclical approaches to modelling employed by mathematicians.
\end{abstract}

Knowing what mathematics to use in a problem situation, knowing when to use it and how to use it are powerful expressions of mathematics competence (National Council of Teachers of Mathematics 2000). However in some classrooms, students' development of mathematics competence is limited to working out of a text book where the answers are provided and little opportunity is given to making thinking visible (Boaler, 2001). As a consequence some students are not given the opportunity to see the expression of mathematics competence as being relevant to out of classroom experiences. Using mathematical modelling to explore mathematics empowers students by allowing them to engage meaningfully with multiple contexts of mathematics use (Galbraith, 1995). Mathematical modelling requires making ideas visible. When thinking is made visible, ideas are able to be revisited for the purpose of making them consistent with the requirements of the task and consistent with the conventions of the mathematics being employed. For the purpose of this paper we adopt Galbraith's (1989) definition of 'open' mathematical modelling which refers to the entire process of doing the mathematics leading from formulating the original problem situation to designing a mathematical model to validate thinking. In short, this approach to mathematical modelling may be said to embody the following cyclical practices (a) making assumptions, (b) formulating questions, (c) developing and interpreting solutions, (d) verifying models, and (e) reporting, explaining, and predicting results (Galbraith, 1989).

\section{Theoretical Framing}

Learning in mathematics is a social activity (Schoenfeld, 2002). When students are provided with an appropriate task, a suitable structure to interact with that task, and scaffolded in their interactions with each other, a form of classroom discourse may be brought about where students are provided with multiple opportunities to construct sophisticated understandings of a mathematics concept or procedure. Within such classroom discourse, the understanding that is demonstrated by an individual student becomes part of the collective understanding of the group (Wertsch, 2002). However, when undertaking an assessment task it is generally accepted that the understanding that is demonstrated is that of the individual. While there are a variety of tools that can be used to assess understanding that range from formal examinations to group projects, the authoring of individual mathematical reports that can be worked on over a period of time and that encourage students to conference with their peers, teachers and others, is an important mechanism for assessing student understanding. In most instances the final product of such

L. Sparrow, B. Kissane, \& C. Hurst (Eds.), Shaping the future of mathematics education: Proceedings of the 33 rd annual conference of the Mathematics Education Research Group of Australasia. Fremantle: MERGA. 
an authoring process is accepted as an individual representation by the student of their analysis of a task and a report of their synthesis of strategies for dealing with the task and the mathematical assumptions upon which conclusions are based. However, even though the end product is accredited to an individual student the process of authoring that product is inherently social, as the student often has discoursed drafts of the work with the teacher and with peers. What is of interest to this paper is how the discourse of the classroom may be evidenced in the authoring of an individual mathematical report.

\section{Method}

The school context referred to in this study is a metropolitan P-12 College that has a mathematics programme from Year 6 through to Year 12 with a major focus on mathematical modelling. Using the framework, 'Teaching for Understanding' (Perkins, 1992), the mathematics department of this College has identified a sequence of generative topics that are explored to develop an understanding of mathematical concepts using mathematical modelling. The Year 12 classes referred to in this paper comprised female and male students studying the Queensland Studies Authority Mathematics B curriculum.

Task content focused on an individual mathematical report given to Year 12 classes of students. The task asked students to use the practices of mathematical modelling to investigate Newton's Law of Cooling. The task is represented in Figure 1.

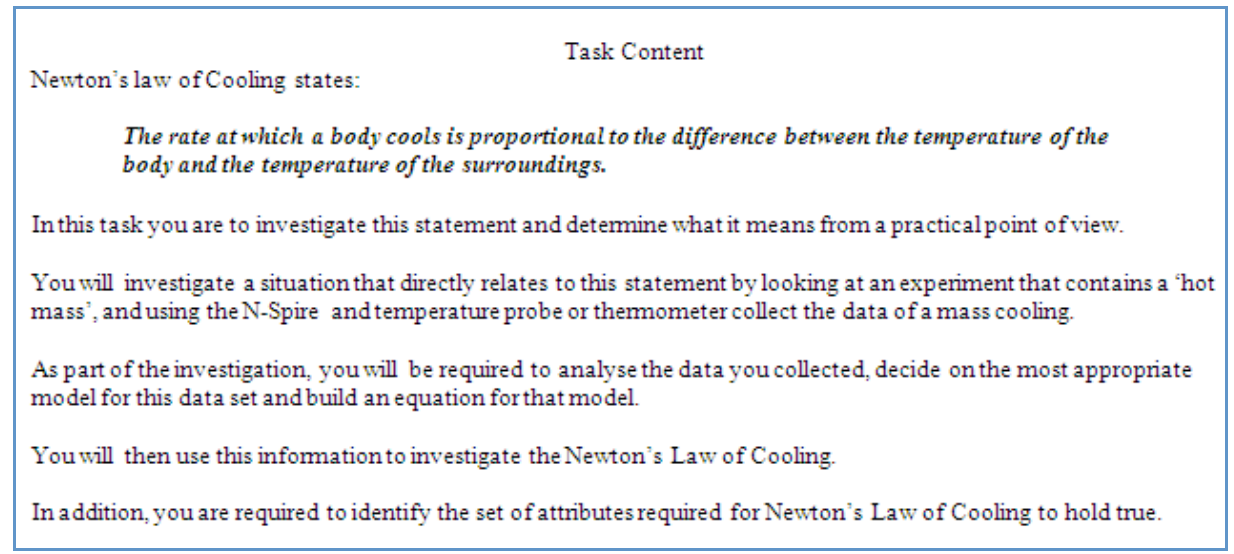

Figure 1. The task.

The task was an out-of-class task enacted over a 6-week period designed to provide summative feedback to students regarding their competence in developing a mathematical model.

Pedagogical context focused on Collective Argumentation (CA) (Brown \& Renshaw, 2000). Students in the Year 12 classes reported in this paper were encouraged to engage in $\mathrm{CA}$ when doing mathematics. CA is an approach to teaching and learning that is based on five interactive principles. The first principle, the 'generalisability' principle, requires that students stop and think about the problem that has been posed in terms of what mathematical concepts and procedures might be useful in building a solution. Students are encouraged to make links with prior knowledge, procedures and understandings. Initially these links may not be strong but as the discussion with the other members of the group and the teacher occur in this and later stages of the process there are opportunities for these links to be strengthened. The second principle, the 'objectivity' principle, requires that ideas, relevant to the task are objectified and communicated to other members of the group. 
Third, the 'consistency' principle requires that ideas which are contradictory to each other or that belong to mutually exclusive points of view must be resolved through discussion. The fourth principle is 'consensus'. Consensus requires that all members of the group understand the agreed approach to solving the problem. If a member of the group does not understand a concept or procedure, there is an obligation on that student to seek clarification, and a reciprocal obligation on the other group members to assist. Finally, in implementing the fifth principle, 'recontextualisation', students re-present the group response to the class for discussion and validation. The principles of CA are used by teachers and students to guide engagement in the discourse of their mathematics classrooms. The aim of this discourse is to enable students to analyse mathematical tasks, to synthesise strategies to undertake those tasks, and to communicate solutions and conclusions to others. This paper explores how the discourse of Year 12 classrooms may be evidenced in the authoring of one student's report that required her to model generalisations developed from investigating Newton's Law of Cooling. The report of this student (Jane) was chosen for analysis because Jane had been exposed to the Principles of CA when doing mathematics for a number of years and regularly used those principles to engage in the discourse of her Year 12 mathematics classroom.

\section{Analysis of Segments of Student Work}

The analysis focuses on Jane's first draft of her mathematical report. As Jane had been exposed to the Principles of CA to engage in the discourse of her classroom for a number of years, the analysis looked for evidence of her incorporating the principles of CA into her mathematical report. We will not be considering the report in total but, due to word constraints, consider sections which link to the principles - Generalisability, Objectivity, Consistency, Consensus, Recontextualisation.

\section{Generalisability}

Jane begins her draft report by detailing what she understands the task to involve (see Figure 2). She outlines the process she is going to employ to investigate Newtons' Law of Cooling. That is, Jane evidences the principle of Generalisability, as she clarifies her understanding of the task and details the approach she is going to adopt. She represents the task from a practical point of view. In doing so, Jane identifies the variables of room temperature, temperature of the probe, and the temperature of the cup, as being important. In the report, Jane does not disclose why she considers these variables to be the ones that need to be controlled, out of the many that are available, but she does indicate procedures that she is going to adopt in an attempt to control them.

\footnotetext{
Newton's Law of Cooling states: The rate at which a body cool is proportional to the difference between the temperature of the body and the temperature of the surroundings. The purpose of this investigation is to explore this statement from a practical point of view. This will be done through the analysis of data collected from the cooling of hot water. The data was collected through the use of a temperature probe and a Ti N-Spire calculator. This data will then be analysed and modelled so as to use this as an example to explore Newton's Law of Cooling.

The controlled variables in this experiment were the outside temperature $(249 \mathrm{C})$, the probe (which was left in the water for 20 seconds before data collection to ensure it was the same temperature as the water) and the mug (the mug was rinsed out with boiling water a few times before data collection, so as to ensure that the mug was not cooling down the water.
}

Figure 2. Identifying variables. 
As seen in Figure 2, Jane has chosen to use graphing calculator technology and a temperature probe to collect data. The use of technology and probe were identified in the task as one method Jane could use to collect data, but, in the end, was a choice she made. Jane's choice of technology provides a clue as to the thinking that Jane is employing. In identifying the variables that need to be controlled and by indicating her choice of the technological tool that she is going to use to assist her investigation, Jane has established a way of thinking and operating about the task. This way of thinking and operating is consistent with the principle of Generalisability that she has been encouraged to use, over a number of years, to direct her initial thinking about a task so that she can engage in the discourse of her mathematics classroom. Through identifying variables and indicating her preferred tool of representation, Jane is able to enter into discussion with others about the task, ask questions of others, share ideas with others, and to monitor her understanding. Jane has also provided a representation of her thinking that can be compared with others who may have highlighted or de-emphasised the same variables and use of technology. As such, Jane's way of initially thinking and operating is consistent with the practice of mathematical modelling that requires a mathematician to formulate assumptions and procedures upon which to base an investigation. This consistency is again demonstrated as Jane objectifies her thinking about the task (see Figure 3).

Variables:

Let $x$ be time in seconds starting where 0 seconds is $x=0$, increasing by $1, e .8 .1=1$ second, $30=30$ seconds.

Let $y$ be temperature in degrees Celsius, increasing by $1, e .8 .1=1$ degree Celsius, $20=20$ degrees Celsius.

It is assumed that the external temperature, although monitored, was infact kept at a constant rate. If this were incorrect it would mean that the temperature which the water was cooling to would be different at different times, creating an unfair experiment. It is assumed that the properties of the container the water was kept in (mug) did not influence the cooling of the water. If this were an incorrect assumption it would mean that the experiment was unfair, and would not be an accurate investigation into Newton's Law of Cooling. It is assumed that no outside forces, air flow, objects with other temperatures, had any influence over the temperature of the water at any point. If this were incorrect then the experiment would be unfair, and would not be an accurate investigation into Newton's Law of Cooling.

Shown below, is a subset of the collected data. For complete data set see Appendix 1 . Also shown below is the scatter plot of $x$ vs. $y$.

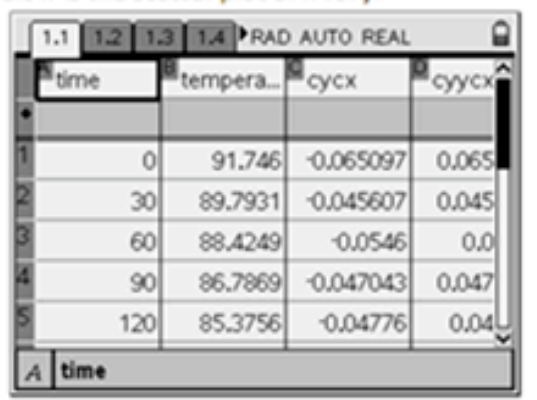

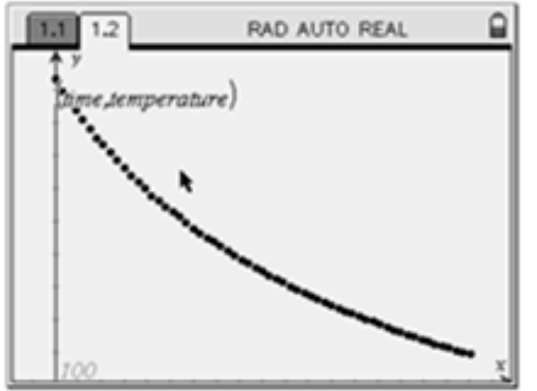

When looked at graphically, it is seen that the data would not be best modelled by a linear model as the curve of the line does not fit the shape of a linear model. This could be modelled by a quadratic equation, but this model would show that at a later time the water would increase in temperature, this does not make sense or fit the context of the data. A quadratic or higher order polynomial would not fit the context of the data as the water would not increase in temperature following the context of the situation. The data may be modelled by an exponential function; it has the same shape that an exponential function would have. The water will eventually reach the external temperature, which is similar to the asymptote of an exponential function. So contextually and mathematically, the exponential function seems to be the better choice of model.

Figure 3. Contextualising thinking. 


\section{Objectivity}

As seen in Figure 3 Jane has contextualised her thinking about the task to the context of a 'fair experiment'. That is, Jane situates her thinking and the procedures within the practices of a 'fair experiment' comparing what she does to the scientific assumptions upon which a 'fair experiment' is based so as to keep her investigation on track. In many ways Jane compares her ideas with the practices of a scientific experiment and explains those comparisons using the practices of mathematics.

In this way, Jane takes her work from the individual to the social plane of reasoning, allowing herself to see what is the same and what is different about her ideas and submitting her ideas to practices that may assist her to view her thinking and procedures from an objective perspective.

This objectivity sets her up for not submitting a report that just looks authoritative, but is authoritative according to the practices of mathematics. In other words, the approach that Jane has taken speaks to the mathematical modelling practice of formulating and solving and requires her to engage in repeated cycles of attaining consistency within her thinking about and doing the mathematical report (see Figure 4).

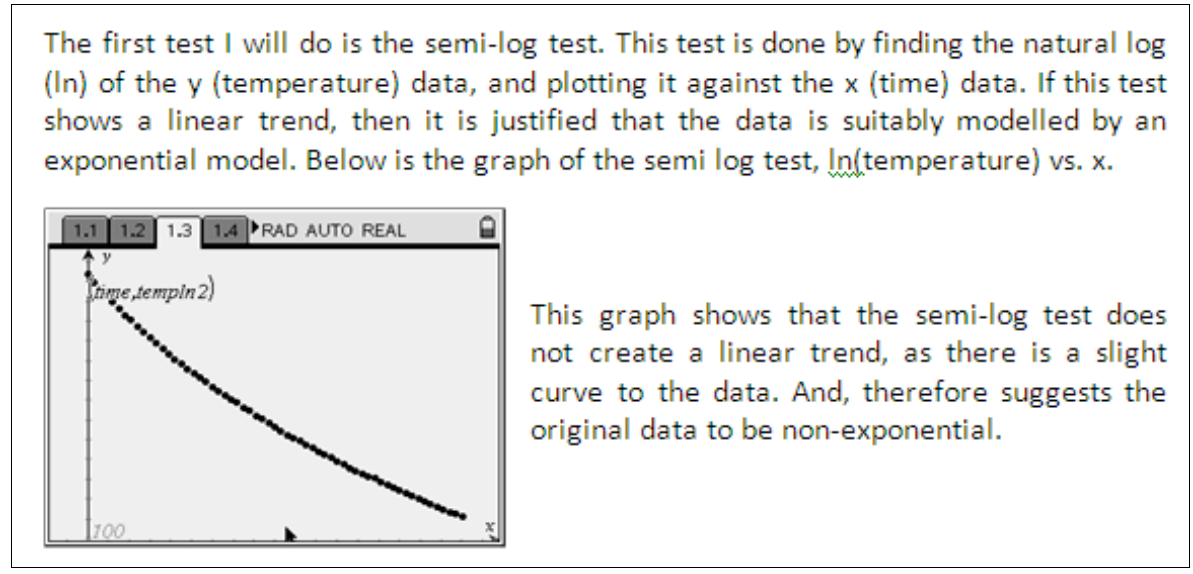

Figure 4. Testing the data.

\section{Consistency}

Within Figure 4 we can see the principle of Consistency operating as Jane gathers and shares evidence about the data fitting an 'exponential' model that satisfies disciplinary constraints. However, in order to satisfy the principle of consistency, Jane needs to justify her ideas and to become conscious of ways of modelling the data that may better fit task requirements. We see this happening in Figure 4 as Jane becomes conscious of "a slight curve" that suggests the "original data to be non-exponential".

In the process, Jane allows her processes of thought as well as the product of her thinking to become visible and open to change. This relates to the modelling practice of interpreting which Jane pursues as she tries to gain consensus between her thinking and the thinking of the mathematical community as represented by her teacher (see Figure 5).

\section{Consensus}

After feedback Jane re-represents her ideas by comparing the change in the values of $y$ divided by change in the values of $x$ versus $y$ graph, noting that the data "follows a linear 
trend". Jane then verifies this trend by representing a "linear regression of the data". In other words, through questioning her own thinking, Jane conducts further inquiry and attains a consensus between her thinking about the task that is based on understanding. In this way, Jane takes the display of her thinking from the individual to the collective plane of functioning as she attempts to use the language of mathematics to express and to verify her thinking. This shift from the individual to the collective is verified in Jane's use of language as she uses the pronouns 'us' and 'we', attempting to regain consistency (see Figure 6) in her thinking - a practice that relates to the modelling practice of verifying.

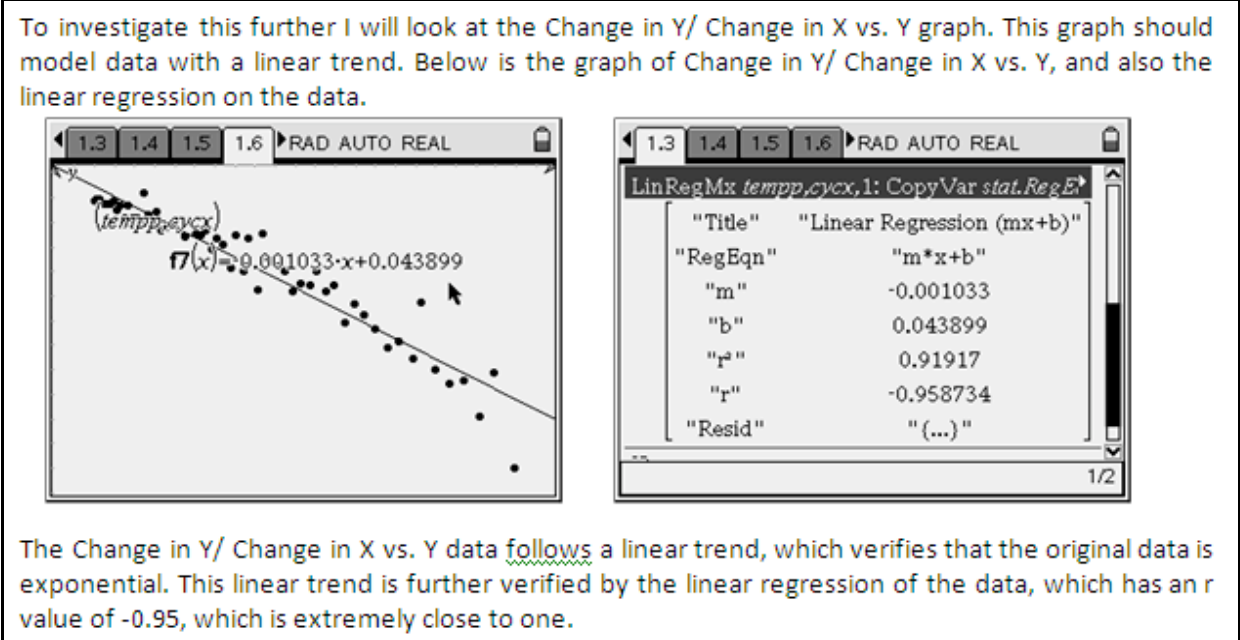

Figure 5. Verifying thinking.

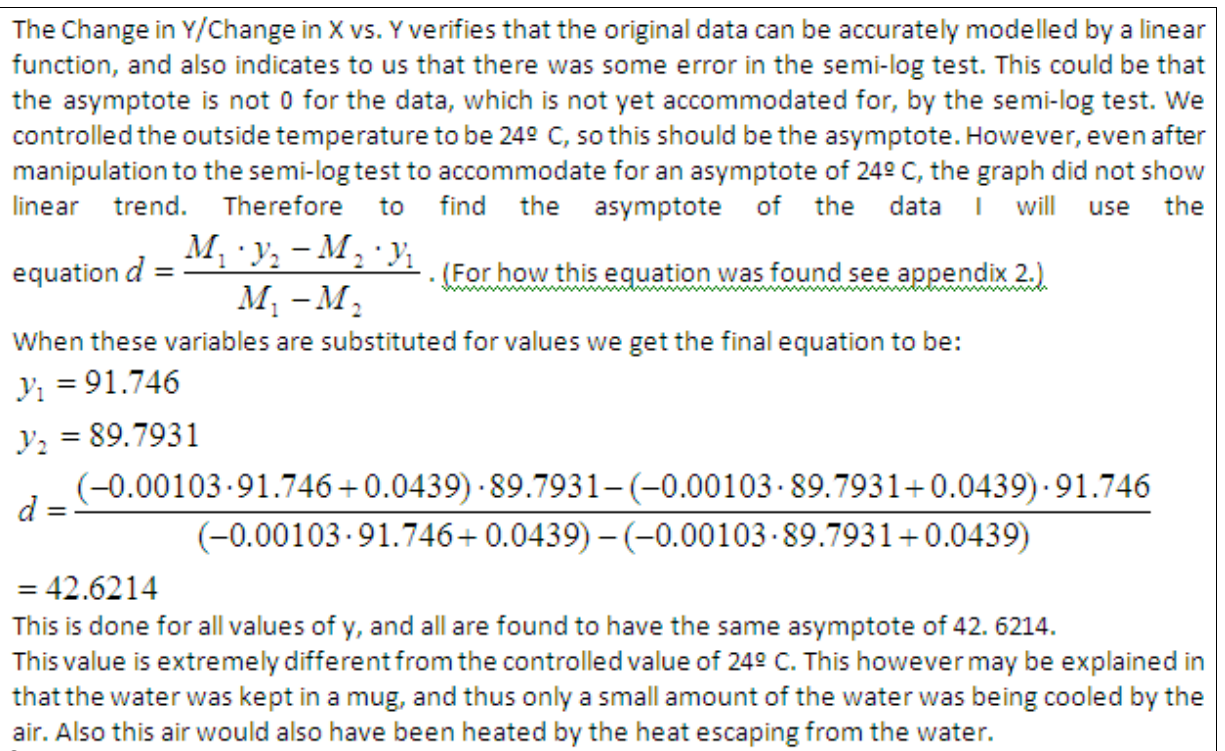

Figure 6. Rethinking the asymptote.

\section{Consistency Revisited}

In attempting to regain consistency in her thinking, Jane declares that there "was some error in the semi-log test" and attributes this error to the value of the asymptote. Jane then 
represents the task in the form of the graph substituting values to find a value for the asymptote using the data and the graph of change in $\mathrm{Y}$ divided by change in $\mathrm{X}$ versus $\mathrm{Y}$.

However, the value for this asymptote is unexpected. Jane then attempts to make this value consistent with the re-representation of her thinking about the task by explaining the value in terms of the "small amount of the water being cooled by the air" and the transfer of heat. Through re-engaging the principle of consistency to guide her investigation, Jane is regulating her attention to the requirements of the task, conceptualising the task within a different set of assumptions and integrating her ideas with scientific understandings. This integration assists Jane to re-gain consensus in her thinking (see Figure 7).

\section{Consensus Revisited}

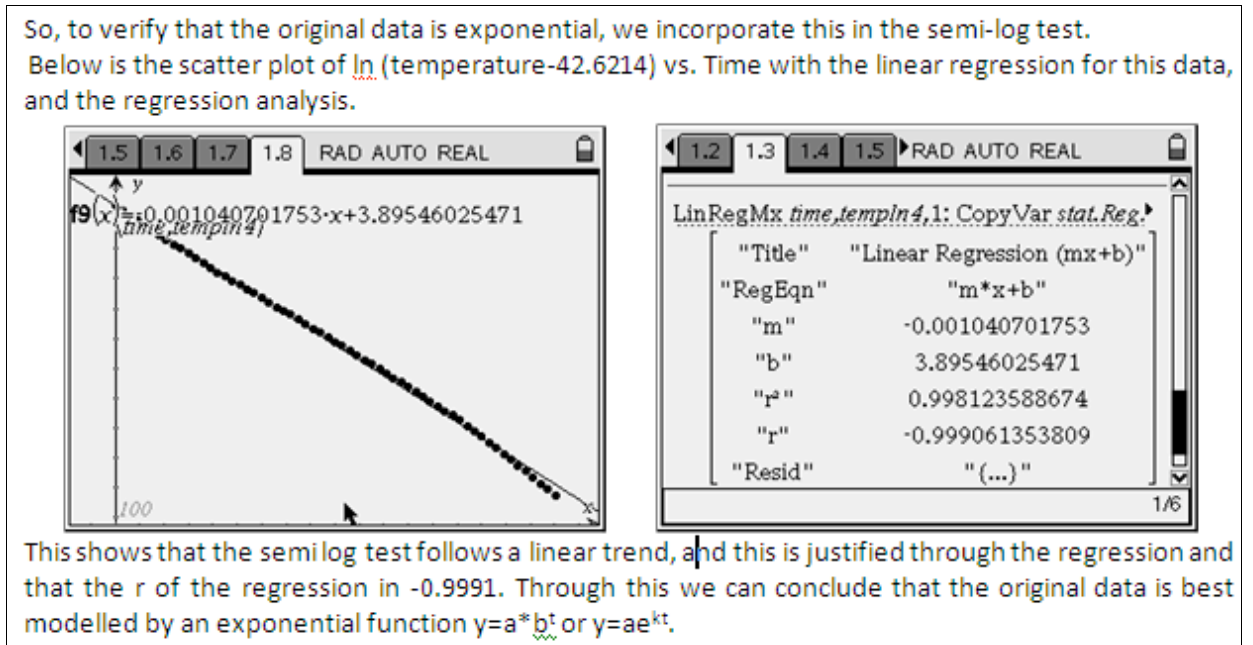

Figure 7. Validating thinking.

Jane's incorporation of the new asymptote into the semi-log test allows Jane to gain consensus between her original representation and her re-representation of the task. In the process, Jane verifies her original approach to doing the task and surrenders the idea that the data is non-exponential. The re-representation of the temperature versus time plot and the construction of the regression analysis reflect her developing understanding of the task. In the process, Jane, again uses the pronoun 'we', acknowledging that her report goes beyond herself to incorporate the discourse of her Year 12 classroom.

\section{Conclusion}

This paper explores the notion that the discourse of the mathematics classroom impacts on the practices that students engage when modelling mathematics. The student whose report was analysed represented her approach to doing mathematical modelling as being one that displayed practices that were congruent with those employed by mathematicians. However, in the process of informing those practices, Jane situated herself within a collective, that is, the discourse of her Year 12 classroom. Through situating herself within this discourse Jane produced a report that not only represented her thinking about the investigation in an objective manner, but a report that evidenced engagement in repeated cycles of consistency and consensus. As such it could be expected that through providing students with access to classroom discourses (e.g., Collective Argumentation) that 
privilege the cyclical practices of mathematical modelling, such practices would be evidenced in the reviewing and editing that students make public when authoring drafts of assessment reports. Such reviewing and editing processes may not only provide insights into student competency, but also insights into the way students represent their engagement with the discourse of their mathematics classroom. For Jane, her draft report would suggest that she is an active participant in the discourse of her mathematics classroom. Whether this relationship between student authoring of assessment reports and their participation in discourse holds true for students other than Jane is a question for further research.

\section{References}

Boaler, J. (2001). Mathematical modelling and new theories of learning. Teaching Mathematics and its Applications. 20(3), 121-127.

Brown, R.A.J., \& Renshaw, P.D. (2000). Collective argumentation: A sociocultural approach to reframing classroom teaching and learning. In H. Cowie and G. van der Aalsvoort (Eds.), Social interaction in learning and instruction: The meaning of discourse for the construction of knowledge (pp. 52-66). Amsterdam: Pergamon Press.

Galbraith, P. (1989). From applications to modelling. In D. Blane \& M. Evans (Eds.), Mathematical modelling for the senior years (pp. 78-86). Parkville: The Mathematical Association of Victoria.

Galbraith, P. (1995). Assessment in mathematics: Developments, innovations and challenges. In L. Grimison \& J. Pegg (Eds.) (1995). Teaching secondary school mathematics. (pp. 289-314). Sydney: Harcourt Brace.

National Council of Teachers of Mathematics (NCTM). (2000). Principles and standards for school mathematics. Reston, VA: Author. Retrieved from http://www.standards.nctm.org.

Perkins, D.N. (1992). Smart schools: Better thinking and learning for every child. New York: The Free Press. Schoenfeld, A.H. (2002) A highly interactive discourse structure. In J. Brophy (Ed.), Social constructivist teaching: Its affordances and constraints (Volume 9 of the series Advances in Research on Teaching) (pp. 131-170). New York: Elsevier.

Wertsch, J. V. (2002). Voices of collective remembering. New York: Cambridge University Press. 